\title{
Why make people patients?
}

\author{
Marshall Marinker Department of Community Medicine, University of Leicester
}

People confront their doctors with three modes of unhealth - disease, illness and sickness. Each is discussed, and the question is asked and answered as to why in this situation people wish to become patients.

The invitation to speak to the title, perhaps to answer the cosmic question, 'Why make people patients?' both flattered and attracted me. Yet I have had the greatest difficulty in choosing what I want to say to you this afternoon. On examining the title my first reaction was that the question, 'Why make people patients?', was poetic but not really philosophic, that it was as unworthy of an answer as certain other unprofound questions like, 'Who is Sylvia?' or Wordsworth's

\section{'O Cuckoo! Shall I call thee Bird}

Or but a wandering Voice?'

But this was not my difficulty. It was not that deep down the question is a shallow one, but rather that it goes to the heart of so much of the critique which is being made of modern medicine; that it begs so many important subsidiary questions. My problem is that in order to answer this question I shall need to acknowledge and celebrate much of the analysis of the medical profession which Ivan Illich makes, and yet to challenge what seem to me to be his unsatisfactory conclusions.

Sociology has been described as a continuing dialogue with the ghost of Karl Marx. Perhaps medicine, or at least health, will become in his own lifetime a continuing dialogue with the ghost of Ivan Illich. The reason that I say ghost is that his eponymous death has already been recorded by Leo Tolstoy in his short story The Death of Ivan Ilyich. Tolstoy tells the story of the final illness of a successful bureaucrat, from the whisper of the first symptom to the sigh of the last breath. There is one passage in which Tolstoy gets to the heart of our matter this afternoon. The doctor has just carried out his examination. The writer observes:

'It was not a question of Ivan Ilyich's life or death, but one between a floating kidney or appendicitis. And this question the doctor, in Ivan Ilyich's presence, settled most brilliantly in favour of the appendix ... He rose, placed the doctor's fee on the table and remarked with a sigh "We sick people no doubt often put inappropriate questions. But tell me, in general, is this complaint dangerous or not?"?

The doctor regarded him sternly over his spectacles with one eye, as though to say, 'Prisoner at the bar, if you will not keep to the questions put to you, I shall be obliged to have you removed from the Court'.

'I have already told you what I consider necessary and proper', said the doctor. 'The analysis may show something more.' And the doctor bowed.

Over a hundred years ago the fictional Ivan Ilyich questioned the bio-engineering view of health; saw through the illusion that diagnosis was a matter only of deeper analysis of the body's structure and function; questioned the social power and the moral rhetoric of the physician. The patient asks, 'What is wrong with me?' and the doctor replies, 'Mind your own business'.

Behind the question, 'Why make people patients?' there lies a belief that patients are created by doctors. From the writings of so many of the commentators whose work I admire - Illich, Irving Zola, John Powles, Michel Foucault - the following proposition seems to emerge: if the role of patient is characterized by a weakening of personal autonomy; by translating the experience of suffering into a description of appearances and behaviours; by changing the request for understanding into a surrender to analysis, then it must be that the role of doctor is inherently destructive of patients.

This view is not lost on the contemporary medical student. Two weeks ago I invited some students from a neighbouring university to come and criticize the curriculum which my department is developing in a new medical school. An outstandingly bright young woman was asked by one of the doctors present when she expected to qualify. She said: 'I take finals in June. But I am no longer sure that I want to be a doctor. I don't want to become like you'. Some of the doctors present in the department were outraged. When I met the young woman's professor a few days later, I recounted the story, congratulated him on his success as a teacher and we congratulated each other on sharing the same sophisticated, liberated and liberating educational goal. I had better specify the nature of his goal. It is not that the medical student should be dissuaded from becoming 
a doctor. It is rather that the medical student should be aware of the power not only for good but also for evil, in the clinical transaction.

W R Houston, reviewing the history of medicine, says that he scans the pages of Hippocrates in vain for any treatment of specific value. He likens the pages of medical history to the log of an oldfashioned sea voyage in which it is noted that on such a day a whale spouted or a flying fish was sighted. The one huge prevailing fact that is never mentioned is the unending green waste of water. In medical history the rarely seen spouting whale or the flying fish are the technical advances: the ever present sea, which may sustain or consume the mariner, is the doctor-patient relationship.

In our own times perhaps the most notable theorist and teacher in the field of this doctorpatient relationship was the psychoanalyst Michael Balint. He had little to say on the fundamental question, 'Why make people patients?' because he began his work with an acceptance of the fact that people are patients. This view stems from a proposition that ill health is always a form of communication, whatever else it may or may not be. In his classic The doctor, his patient and the illness, Balint wrote:

'Every illness is also the vehicle for a plea for love and attention. One of the commonest conflicts of man is caused by the discrepancy between his need for affection and the amount and quality of the affection which his environment is able and willing to grant him.'

There seems to be, as Desmond Morris suggests, a traceable theoretical basis which accounts both for the grooming behaviour of chimpanzees on the one hand, and the treatment of patients by doctors on the other.

\section{Three modes of unhealth}

I want now briefly to rehearse the three different modes of unhealth with which the doctor is confronted.

\section{DISEASE}

The first mode of unhealth is disease. This is a pathological process, most often physical as in throat infection, or cancer of the bronchus, sometimes undetermined in origin, as in schizophrenia. The quality which identifies disease is some deviation from a biological norm. There is an objectivity about disease which doctors are able to see, touch, measure, smell. Diseases are valued as the central facts in the medical view. It is in this sense that the patient has often been described as 'the accident of the disease'.

In his short story, Tolstoy describes with cruel precision the diagnosis of Ivan Ilyich's disease. One specialist favoured the floating kidney: another said that 'There was just one little thing $\stackrel{\frac{8}{2}}{\stackrel{2}{2}}$ the least trifle - wrong in the intestinal appendix Later that night the pain returned and Tolsto describes how 'in a flash the trouble presented. itself in quite a different guise. " "Intestina秀 appendix! Kidney!" he said to himself. "It's nof a question of appendix or kidney but of life an ... death",'

Much of the critique of the second Ivan Illich is based on the not so modern myth (it is in facof already rooted in eighteenth century medicine)? the myth that the truth of an unhealth muș eventually yield to the dissecting eye. But the destructiveness of a caring technology powered by contemporary tools was beyond the imagination that Tolstoy displayed in his story. At one of mP most recent seminars with young doctors I was presented with a patient who had that week beebo submitted to an operation to sever the vagus nerve $\mathrm{He}$ had a year-long history of abdominal pains and was said to have vomited blood. No blood was ever demonstrated in his vomit and no less than five barium examinations of the stomach. and a fibrogastroscopy had yielded up no guiltte secrets. Totally neglected in his general praco titioner's notes was the chronicle of non-attendancE at school because of a tendency to chest infections and non-attendance at work for year after yea because of chest pain and backache which com\% municated no clinical sign or message of encourage $\stackrel{\mathbb{Q}}{2}$ ment to the investigating clinicians.

In a brilliant essay On the limitations of modern medicine, John Powles (1973) writes:

'In recent decades ... scientific technology of an' engineering kind has gained an overwhelming dominance in the mediation between industrial man and disease ... This response pervades the whole of contemporary medical culture - the organisation of medical care, the education of doctors and the character of the doctor-patient relationship.'

\section{IILNESS}

The second mode of unhealth is illness. Illness is a feeling, an experience of unhealth which is entirely personal, interior to the person of the $N$ patient. Often it accompanies disease, but the disease may be undeclared, as in the early stageso of cancer or tuberculosis or diabetes. Sometimeso illness exists where no disease can be found. $\bar{\varnothing}$ Traditional medical education has made the? deafening silence of illness-in-the-absence-of- $T$ disease unbearable to the clinician. The patient can offer the doctor nothing to satisfy his senses $-\stackrel{8}{\rightarrow}$ he can only bring messages of pain to the doctor,, from an underworld of experience shut off for ever from the clinical gaze. The traditional remedy for this distress (I am of course talking about:응 the distress of the doctor and not the distress of the patient) is to translate the illness into the을 
language of diseases that do not require objects available to the doctor's eyes, ears or hands. I am talking about psychiatric language. Words like 'functional overlay', 'inadequate personality', 'hysteria' or 'neurotic', words heavy with the semantic overtones of personal abuse provide us with the rhetoric (if not the conviction) of clinical common sense. The advent of the behavioural sciences in the curriculum of the undergraduate may help him to understand the nature of this sort of dialogue between doctor and patient, but they do not pierce the silence and so they cannot frame for the doctor a meaningful reply.

\section{SICKNESS}

The third mode of unhealth is sickness. If illness is an interior and personal mode for the patient, sickness is the external and public mode of unhealth. Sickness is a social role, a status, a negotiated position in the world, a bargain struck between the person henceforward called 'sick', and a society which is prepared to recognize and sustain him. The security of this role depends on a number of factors, not least the possession of that much treasured gift, the disease. Sickness based on illness alone is a most uncertain status. But even the possession of disease does not guarantee equity in sickness. Those with a chronic disease are much less secure than those with an acute one; those with a psychiatric disease than those with a surgical one. The diseases of the old are less highly regarded than those of the young; I do not dare to suggest that diseases of women are inferior to those of men. Best is an acute physical disease in a young man quickly determined by recovery or death either will do, both are equally regarded. The hero of Tolstoy's story, once he had progressed from the vague symptoms of a bad taste in his mouth and an irritability with his nagging wife to the recognition of a quickly spreading cancer, was utterly secure in his sick role. The young man with months of abdominal pain and vomiting, who finally came to surgery, was not nearly so secure in his sick role, even when the surgeon in desperation used his scalpel to penetrate the deafening silence of his illness.

\section{Semaphores of signs and symptoms}

A recognition of these three modes of unhealth may help us to understand the different, often contradictory and puzzling semaphores of the patient's symptoms and signs. Of itself it does not constitute an explanation of the message. What I wish now to suggest to you is that the act of communicating is what medicine is all about. In the words of Ashley Montague, that medicine should be regarded neither as an art nor as a science in itself, but as a special kind of relationship between two persons, a doctor and a patient.
The word patient is one which describes not simply a role but a personal relationship. It is a half-word, like lover or confidante, a word which describes an encounter with another. Winnicott used to say that he could not describe an infant without also describing the mother: what he recognized as a clinician was the unity of motherand-child. It is a commonplace of clinical teaching that when a medical student describes the symptoms and signs of a disease, he will be asked to relate them to the patient as a person. The thinking here is that each individual will modify the generality of the disease, say a peptic ulcer, by his genetic constitution, by his environmental experience, by the way he presents his complaint and copes with his suffering. Such clinical teaching seems to place the person at the centre of the stage - but it is an illusion. The person remains only the vehicle for, the accident of, that which alone speaks to doctors the disease. Much more recent in clinical teaching is the suggestion that not only must the student relate the problem to the patient, but also to the doctor. That what is diagnosed and treated is the outcome of a bargain, the product of a collusion between doctor and patient - it is on the basis of such agreement between two people that the decision is made to sever the vagus nerve or to discuss the patient's anger with his parents, or to prescribe a tranquillizer or an antidepressant. What the patient presents is his unorganized, chaotic unhealth. The doctor sorts and shapes this presentation, makes something of it - a diagnosis - and offers it back to the patient.

\section{Do people want to be patients?}

What evidence do I have that people want to be patients? I could claim that the roles of doctor and patient, and hence their relationship, is both historical and universal; that long before the advent of specific remedies, patients went to doctors for help and endured then, as often they endure now, cures worse than the disease. But the evidence is more readily available from everyday clinical experience. I offer you the experience of general practice, although the experience of hospital medicine would be no different: general practice is a better place for observing the interaction between patients and doctors only because the clear forms of unhealth are not so encrusted, as they are in the hospital, with the immemorabilia of technological data.

Almost all of the studies of the doctor-patient relationship in general practice reveal the extraordinary toughness and endurance of this relationship. It seems to survive the vicissitudes of undiagnosed disease, inappropriately treated symptoms, moments of anger and years of disappointment. Whether the relationship is described as a collusion, or in the words of Michael Balint, 
'a mutual investment company', something quite unconnected with the nature of unhealth seems to bind the doctor and patient together. Ann Cartwright (1967), in her study of general practice in this country, found that a large majority of patients were happy with their general practitioners: the great majority of changes of practitioner, nearly nine-tenths, occurred either because the patient moved or because the doctor retired or died. And this in the setting of crowded waiting rooms, five minute consultation and professional discontent. It is too feeble to attribute the endurance of these relationships to patient docility or to bureaucratic inertia alone.

Some years ago, Professor Desmond Pond and I were associated with the late Michael Balint in a study which illuminated an aspect of clinical practice which had not been researched before and which throws light on our problem today. We looked at patients who received a repeat prescription for some medication from their general practitioners over a long period - sometimes months, more often years. We found an interesting and discreet social and psychological profile in these patients, but very rarely any disease process which could explain the patient's reason for demanding a repeat prescription with clockwork regularity, or the doctor's motivation for continuing the prescription. In the period before the repeat prescription was instituted, there were characteristically a number of episodes of illness, most often associated with fruitless hospital investigations. After the institution of a regime of repeat prescriptions (usually for a drug of low potency and low dose) the doctor-patient relationship became peaceful and the patient seemed to function more or less effectively in his own environment. The content of subsequent consultations became ritualized, seemingly trivial, unrelated to the presentation of illness, sometimes reduced to no more than a request for the prescription, and this often by proxy, letter or telephone. For most of this sizeable minority of patients in general practice, the transaction could not be understood in terms of any of the three modes of unhealth which I have outlined this afternoon: the patient had no demonstrable disease, he no longer complained of an illness and he rarely seemed to occupy the role and status of sick person.

The act of consulting, the giving and receiving of the prescription, seemed to constitute its own reason. These mysterious consultations occur much more often than a traditional medical education will lead you or allow you to recognize. A great deal of the controversy about the usefulness of counselling hinges on the question of whether counselling is an end in itself, or whether it produces something some sort of resolution, some measurable change in behaviour which can be labelled healthy. In his monograph The faith of the counsellors, Paul Halmos inclines to the view that counselling is an act off tenderness which is total, indivisible and personas. He says '... the ideology of counselling has become an ally of love's growth among men'. The question 'Why make people patients?' becomes transformeof in the process of an enlightened medical education to the statement made to me by the young medicat student, 'I am no longer sure that I want to become a doctor'.

It is possible for a person to experience unhealthis to have disease, to feel ill, to be sick, withou $\vec{f}$ becoming a patient. To become a patient is to establish a healing relationship with another why articulates society's willingness and capability to help. The exposition of modern medicine's in adequacies, the analysis of the social subversiveness of doctors which Ivan Illich gives us, is a most valuable text. But a text for what? A manifesto which calls for the abolition of the role of patient (and I have suggested that this is implicit in the call to abolish the role of doctor) ignores the evidence of man's need to be cared for and to believe. Medical nemesis may or may not become the text for a more healthy culture. Like changes' in the pattern of diseases and treatments, thפ growth of preventive medicine and public healt measures, the advent of Illich's sanitary utopi 형 will only change the vocabulary with which doctores and patients talk to one another: history suggest that the fact of the dialogue will not be changed In any event, I suggest that a society withou unhealth would not be a utopia but a particulas kind of hell.

Medical nemesis, whatever its author intends must become part of the text for a reform of the medical curriculum. That some contemporary students, confronted with the model of medical. care which their teachers present, can say, 'I an's no longer sure that I want to be a doctor. I don' want to become like you.' provides some evidence that the reform may already be upon us.

\section{References}

Balint, M, (1974). The Doctor, his Patient and the Illness. Pitman, London,

Balint, $M$, Hunt, J, Joyce, $D$, Marinker, $M$ and Woodard $\bar{C}$ J. (1970). Treatment and Diagnosis. Tavistock Presso London.

Illich, Ivan (1975). Medical nemesis. Calder E Boyars, London.

Morris, Desmond (1967). The Naked Ape, J. Cape London.

Powles, John (1973). On the limitations of moderns medicine, Science Medicine and Man. I, I-30.

Tolstoy, Leo, The Death of Ivan Ilyich, The Cossack andक other stories, Penguin, London, 1974. 